\title{
Embryo implantation failure and other reproductive defects in Ube2q1-deficient female mice
}

\author{
Pawel Grzmil ${ }^{1,2}$, Maria E Altmann ${ }^{1}$, Ibrahim M Adham ${ }^{1}$, Ulrike Engel ${ }^{1}$, Hubertus Jarry ${ }^{3}$, \\ Stefan Schweyer ${ }^{4}$, Stephan Wolf ${ }^{1}$, Johanna Mänz ${ }^{1}$ and Wolfgang Engel ${ }^{1}$ \\ ${ }^{1}$ Institute of Human Genetics, University of Göttingen, Heinrich Düker Weg 12, 37073 Göttingen, Germany, \\ ${ }^{2}$ Department of Genetics and Evolution, Institute of Zoology, Jagiellonian University, 30-060 Kraków, Poland, \\ Departments of ${ }^{3}$ Clinical and Experimental Endocrinology and ${ }^{4}$ Pathology, University of Göttingen, 37073 Göttingen, \\ Germany
}

Correspondence should be addressed to P Grzmil at Institute of Human Genetics, University of Göttingen;

Email: pawel.grzmil@med.uni-goettingen.de

\begin{abstract}
The ubiquitination process is indispensable for proteome regulation. Three classes of ubiquitin (Ub)-related proteins can be distinguished: E1, E2 and E3. Proteins from the E2 class are responsible for the transfer of Ubls from E1 to the target protein. For this activity, interaction with class E3 ligases is usually required. Ub-conjugating enzyme E2Q 1 (UBE2Q1) belongs to the E2 class of Ub-related enzymes and is demonstrated to be involved in the regulation of membrane B4GALT1 protein. Here, we demonstrate that human UBE2Q1 and mouse Ube2q1 are widely expressed and highly conserved genes. To elucidate the function of UBE2Q1 protein, we generated knockout mouse model. No overt phenotype was detected in UBE2Q1-deficient males, but in mutant females, pleiotropic reproductive defects were observed including altered oestrus cycle, abnormal sexual behaviour and reduced offspring care. Moreover, in the uterus of mutant females, significantly increased embryonic lethality and decreased implantation capacity of homozygous mutant embryos were noticed. We found that Ube2q1 is not expressed in the uterus of non-pregnant females but its expression is up-regulated during pregnancy. Taken together, Ube2q1 is involved in different aspects of female fertility.

Reproduction (2013) 145 45-56
\end{abstract}

\section{Introduction}

Ubiquitination is involved in selective protein degradation, which is an important part of cellular proteome regulation. The essential step in this process is covalent binding of ubiquitin (Ub) or Ub-like proteins (Ubls) to the substrates (for review, see Dye \& Schulman (2007)). The way Ub and Ubls are processed and attached to the target protein is highly conserved, three-step process, involving the subsequent participation of activating enzymes (E1), conjugating enzymes (E2) and ligase activity (E3) (Pickart \& Eddins 2004). The central role in this cascade is assured by members of the E2 family, which consists of dozens of proteins identified in higher eukaryotes (Hofmann \& Pickart 2001, Burroughs et al. 2008). E2 enzymes drive the specificity of Ub or Ubls conjugation and thus determine the fate of targeted proteins (reviewed in van Wijk \& Timmers (2010)). A characteristic feature of this family is the presence of a 150-200 amino acid Ub-conjugating domain that serves as a binding site for E1s, E3s and Ub/Ubls (Hofmann \& Pickart 2001, Burroughs et al. 2008, van Wijk \& Timmers 2010).
Increased ubiquitination was reported in the uterus during embryo implantation (Bebington et al. 1999a, $1999 b, 2000,2001)$; thus, the proper control and turnover of the key signalling protein activity seems to play critical role for initiation of pregnancy. This might also be emphasized by the observation that $U b$ is accumulated in trophoblast of expanding bovine and mouse blastocysts (Sutovsky et al. 2001). The $26 \mathrm{~S}$ proteasome, which regulates the proteolytic activity of the matrix metalloproteinases (MMPs)-2 and -9 , is required during implantation process (Wang et al. 2004). The important function of other ubiquitination-related proteins such as the Ub-conjugating enzyme UBCM4 (Harbers et al. 1996), the proteasome activator PSME3

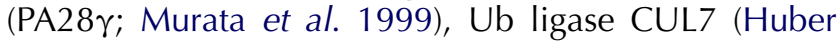
et al. 2005) and FBXW8 (Tsutsumi et al. 2008) was demonstrated by the phenotype of mouse models with placenta and intrauterine embryonic growth retardation. The Smurf2 gene, encoding E3 class protein, is involved in trophoblast cell invasion and embryo implantation (Yang et al. 2009). $\beta$-Catenin ubiquitination through two E3 ligases, BTRC and CACYBP, plays an important role during decidualization (Herington et al. 2007). Also, E2s 
were demonstrated to be involved in the implantation process. Rabbit Ube2q2 (also known as UBCi) expression is up-regulated in the endometrial epithelial cells by the embryo implantation event (Melner et al. 2004). The up-regulation of E2 conjugating enzymes from the 1 to 8 protein families was detected in the uterus of pregnant bovine (Pru et al. 2001).

Human UBE2Q1 was identified among other genes related to epidermal differentiation complex (EDC) and epidermis maturation by screening of keratinocyte cDNA library (Marenholz et al. 2001). Human and mouse UBE2Q1 proteins share $98 \%$ identity and both contain a consensus sequence for $\mathrm{Ub}$ binding at its C-terminus. It has been demonstrated that mouse UBE2Q1 is an active E2 class Ub-conjugating enzyme. The N-terminal end of this protein is critical for the binding and internalization of UDP-Gal:betaGlcNAc beta 1,4-galactosyltransferase, polypeptide 1 (B4galt1, also known as GalT1) (Wassler et al. 2008). The authors detected the expression of Ube $2 q 1$ in the inner cell mass (ICM) and in the trophectoderm cells of early blastocyst. To elucidate the role of this gene in mammals, we generated a knockout mouse model in which the Ube2q1 was deleted by homologous recombination. We discovered that this gene plays a role in female fertility and embryo implantation process.

\section{Results}

\section{Expression pattern and evolutionary conservation of human UBE2Q1 and mouse Ube2q1}

In order to study the expression of human UBE2Q1 gene, total RNA isolated from different tissues was hybridized with ${ }^{32}$ P-labelled $1 \mathrm{~kb}$ cDNA fragment containing exons 5-13. Two transcripts, 2.4 and $4 \mathrm{~kb}$, were detected in all the analysed tissues. RNA quality was proven by membrane rehybridization with human $A C T B$ probe (Fig. 1A). It was published that the Ube2q1 gene is highly conserved among many species (Schulze et al. 2003, Wassler et al. 2008). Therefore, we used human $U B E 2 Q 1$ cDNA probe to hybridize with RNA isolated from testis or brain from different mammals and one bird species. The human probe detected single transcript in RNA isolated from bovine, pig, goat, rabbit $(2.4 \mathrm{~kb})$ and pigeon $(2.2 \mathrm{~kb})$ and two transcripts in mouse, rat (2.4 and $4 \mathrm{~kb}$ ) and rhesus (2.2 and $2.4 \mathrm{~kb}$ ) (Fig. 1B). Next, we have analysed the expression of Ube2q1 in mouse tissues by RT-PCR. Using AltRTPCRFP and AltPCRRP primers, a 467 bp product was amplified in all the tissues analysed except the uterus of non-pregnant female. To prove primer specificity, negative control without reverse transcriptase was used. The cDNA quality was verified using Hprt-specific primers (Fig. 1C). These results indicated that human and mouse UBE2Q1/Ube2q1genes are expressed in many tissues and are highly evolutionary conserved.

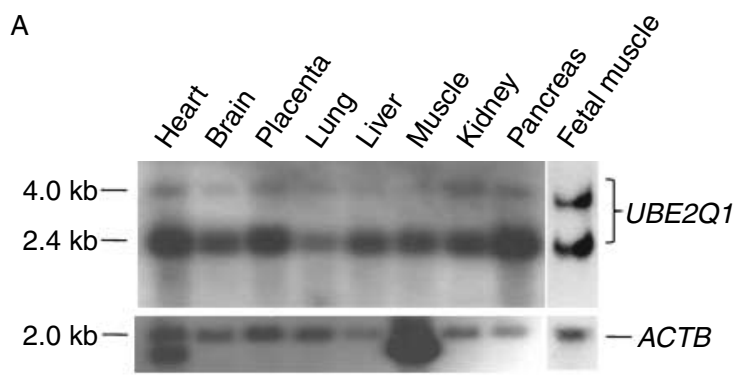

B

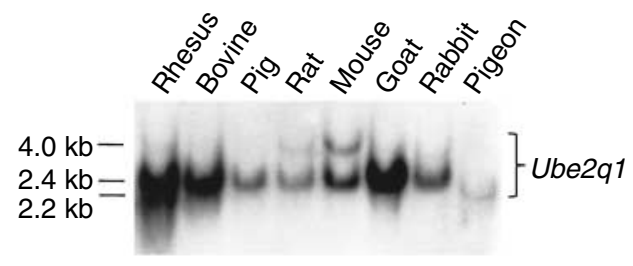

C

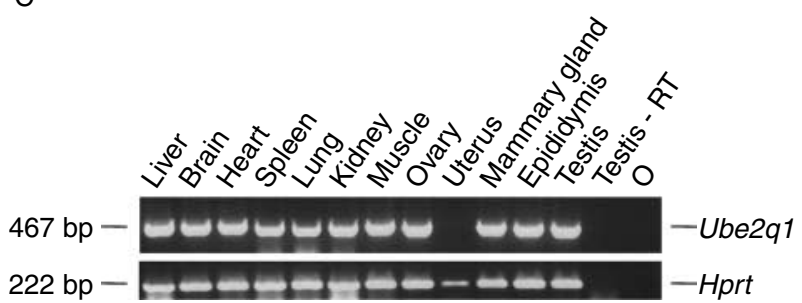

Figure 1 Analysis of ubiquitin-conjugating enzyme E2Q family member 1 (Ube2q1) expression. The expression of human UBE2Q1 was analysed in different tissues by northern blot with ${ }^{32} \mathrm{P}$-labelled $1 \mathrm{~kb}$ cDNA fragment containing exons $5-13$ as a probe (A). 2.4 and $4 \mathrm{~kb}$ transcripts were detected in all tissues analysed (upper panel). The RNA quality was proven by membrane rehybridization with human ACTB probe (lower panel). (B) The same cDNA probe was used to detect the Ube $2 q 1$ transcript in RNA isolated from brain or testis of different species. One transcript was observed in RNA isolated from bovine, pig, goat, rabbit $(2.4 \mathrm{~kb})$ and pigeon $(2.2 \mathrm{~kb})$, and two transcripts were present in mouse, rat (2.4 and $4 \mathrm{~kb}$ ) and rhesus (2.2 and 2.4 kb) RNAs. (C) The expression of mouse Ube $2 q 1$ was analysed using RT-PCR. The 467 bp PCR product was amplified in all tissues analysed except for the uterus of non-pregnant female. cDNA quality was demonstrated using the Hprt-specific primers.

\section{Generation of the Ube2q1-deficient mouse}

To determine the function of Ube2q1, we used a gene targeting approach to generate homozygous Ube $2 q 1^{-1-}$ null mice. Mouse Ube2q1 gene was deleted by homologous recombination with the knockout vector containing neomycin (neo) and thymidine kinase cassettes. After electroporation of the knockout vector into ES cells, exons $5-11$ of Ube2q1 were replaced by the neo cassette (Fig. 2A). ES clones harbouring recombinant allele were identified using Southern blot analysis (Fig. 2B). The $5^{\prime}$ external probe detected a $13 \mathrm{~kb}$ EcoRI fragment of the recombinant allele and an $8 \mathrm{~kb}$ EcoRI fragment of the wild-type allele. Chimeric mice were generated by aggregating 10-15 compact ES cells, 

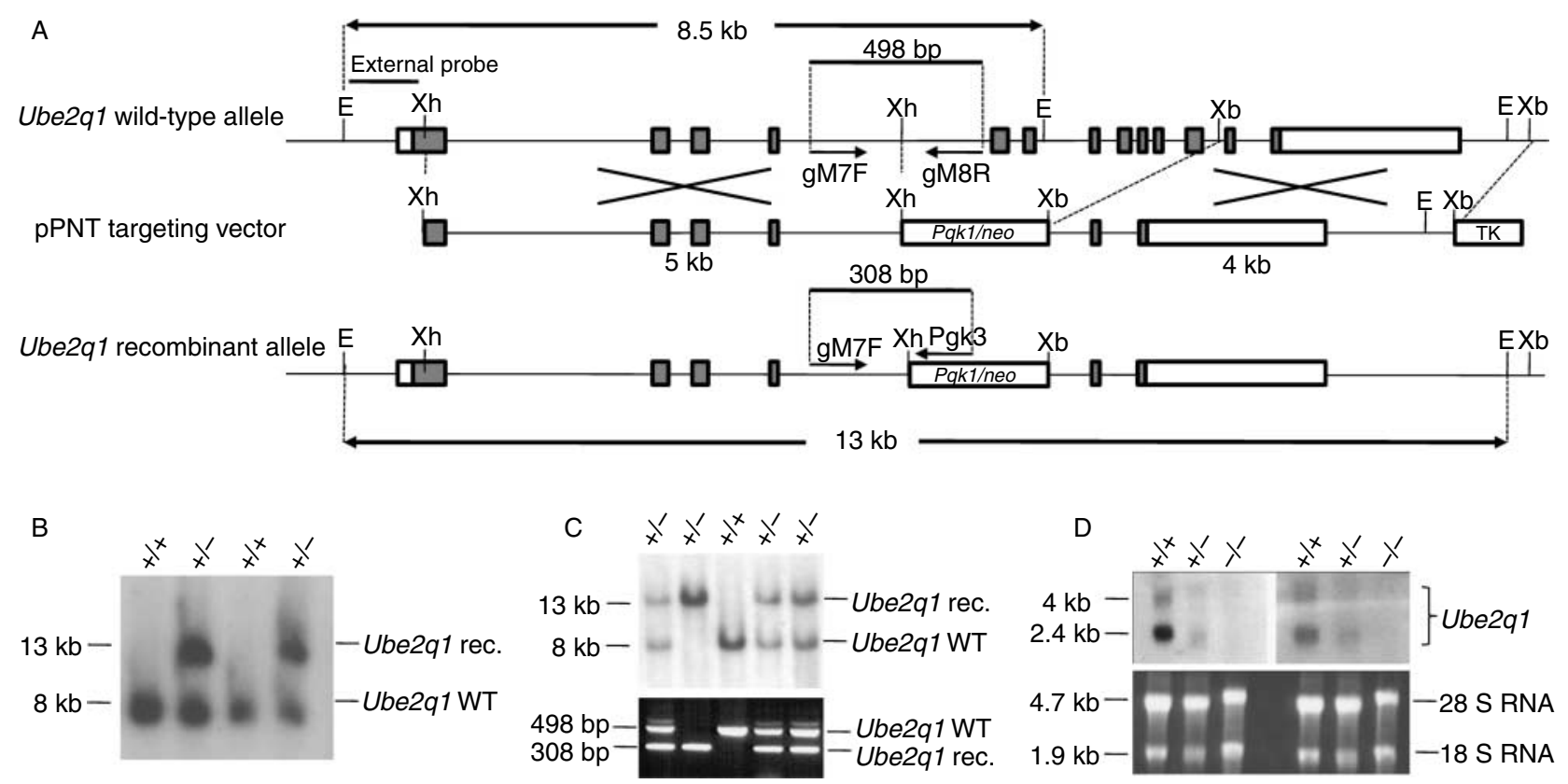

Figure 2 The strategy of targeted disruption of the mouse Ube2q1 gene. (A) Schematic structure of the wild-type and recombinant Ube2q1 alleles is shown. Relevant restriction sites (Xh-Xhol; E-EcoRI and Xb-Xbal) and applied primers (gM7F, gM8R and Pgk3) are given. The knockout strategy was designed to replace exons 5-11 with the Pgk1/neo cassette. The $5.0 \mathrm{~kb}$ long genomic Xhol fragment and $4 \mathrm{~kb}$ long Xbal fragment of mouse Ube2q1 gene were used as $5^{\prime}$ and $3^{\prime}$ homologue sequence in the knockout vector respectively. (B) Genomic DNA from electroporated ES cell clones was digested with EcoRI enzyme and probed with 32 P-labelled 5' external probe. Southern blot analysis shows an 8 kb band representing the wild-type Ube2q1 allele (Ube2q1 WT) and a $13 \mathrm{~kb}$ band for the recombinant allele (Ube2q1 rec). (C) The F2 generation was genotyped by Southern blot and PCR using genomic DNA isolated from mouse tails. In the Southern blot, WT and recombinant allele were detected as describe earlier. In the PCR assay, a product of 498 bp was amplified from the wild-type Ube2q1 allele and a 308 bp product from mutated Ube2q1 allele. +/+: wild type, $+/-$ : heterozygous, $-/-$ : mutant homozygous. (D) The expression of Ube2q1 was analysed in the knockout mice using northern blot and cDNA

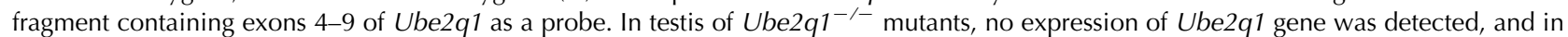
Ube $2 q 1^{+/-}$animals, the signal was weaker than that in Ube $2 q 1^{+/+}$(upper panel). RNA integrity and quantity were monitored by ethidium bromide staining (lower panel).

carrying the homologous recombinant allele, with two 2.5-day-old embryos of the CD1 mouse strain as described previously (Nagy \& Rossant 1993). Male chimaeras were mated with $129 / \mathrm{Sv}$ females to establish the knockout line on 129/Sv genetic background. Heterozygous animals were identified by PCR using gM7F, gM8R and Pgk3 primers (Fig. 2A) and crossed to obtain homozygous mutants. The genotype of the first pups from the heterozygous breeding was determined by Southern blot and PCR (Fig. 2C), while the genotype of all the following offspring was determined by PCR only. To confirm the null mutation in the Ube2q1 locus, northern

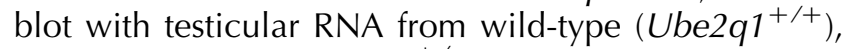

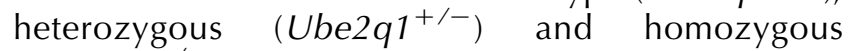

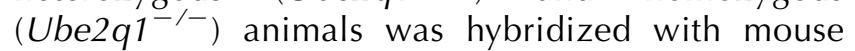
cDNA probe containing exons 4-9 of the Ube2q1. No expression of Ube2q1 gene was detected in RNA from Ube $2 q 1^{-/-}$mutants, while in Ube $2 q 1^{+/-}$animals, the expression level was weaker than that in Ube2q1+/+ testis. The quality and integrity of the RNA samples were visualized by ethidium bromide staining (Fig. 2D). Furthermore, the expression of Ube2q1 was also analysed in many other tissues of Ube2q $1^{-/-}$male and female, but no signals were detected (data not shown).

\section{The phenotype of Ube2q1 $1^{-/-}$mice}

Heterozygous males and females did not demonstrate any overt phenotype, the fertility was normal and the litter size was not significantly different from wild-type breeding (Fig. 3A). No significant difference in spermatozoa number, sperm morphology and motility was observed between homozygous mutant and wild-type males, and sperms of Ube $2 q^{-1-}$ animals undergo normal acrosome reaction (data not shown). In contrast, homozygous mutant females demonstrated pleiotropic reproductive defects. They needed markedly longer mating time to become pregnant with either wild-type or homozygous mutant males when compared with Ube $2 q 1^{+/+}$or Ube2 $q 1^{+/-}$females. While wild-type females gave birth to their first litter in 8th-9th week of age, the majority of Ube2q1-/- females had their first litter much later, namely around 10th-12th week of age.

To further elucidate the effect of Ube2q1 deletion on the fertility, different types of breeding were established and analysed. The litter size of Ube $2 q 1^{-/-}$females, which were mated with wild-type or homozygous mutant males, was significantly reduced comparing with wild-type breeding $(P<0.001$, Fig. 3A). When 

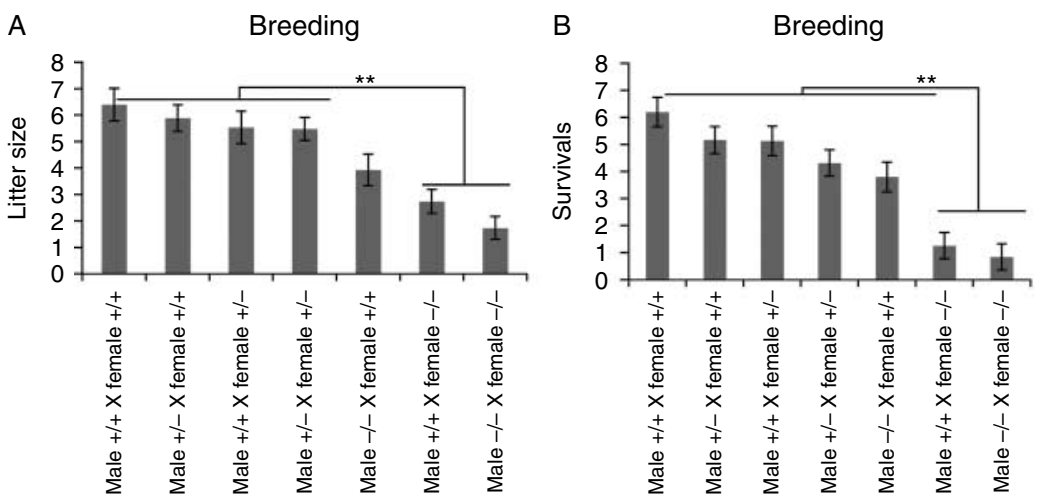

C

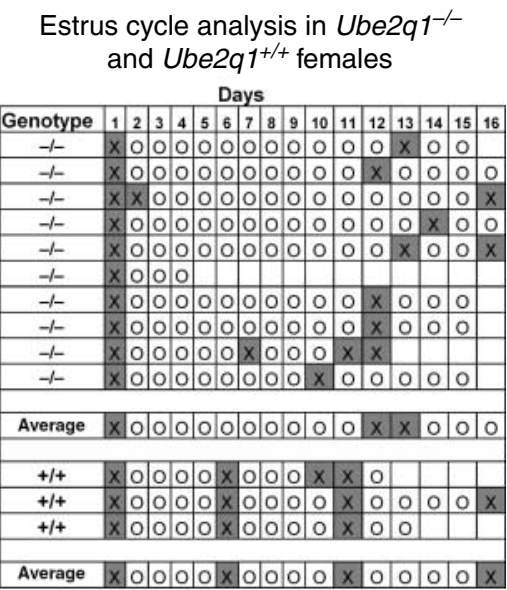

D

Vaginal plug frequency in Ube2q $1^{-/-}$and $U b e 2 q 1^{+/+}$females

Days

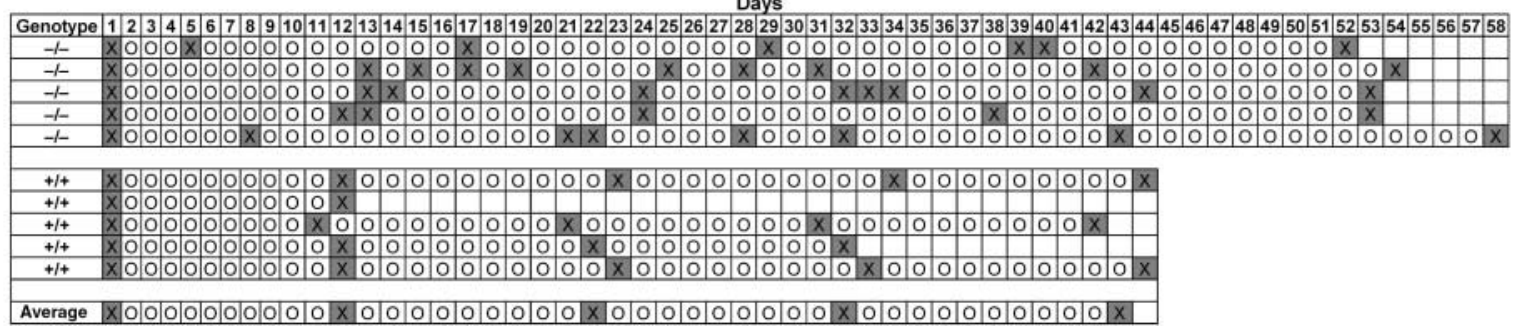

Figure 3 Phenotype of Ube $2 q 1^{-/-}$mutants. The litter size was significantly reduced when the Ube2q1-/- females were mated with wild-type or homozygous mutant males, when compared with wild-type or heterozygous breeding (A). The litter size of homozygous mutant male mated with wild-type female was significantly lower compared with wild-type breeding $(P=0.03)$; however, it was not significantly different from heterozygous or heterozygous and wild-type pairs $(P>0.05)$. (B) In the breeding of homozygous females, the number of pups that survived the 30 days post partum

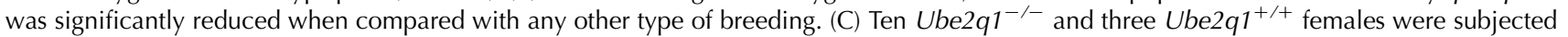
to vaginal smear examination to determine the oestrus cycle. The filled box marked with $\mathrm{X}$ represents the day when oestrus was noticed. On an

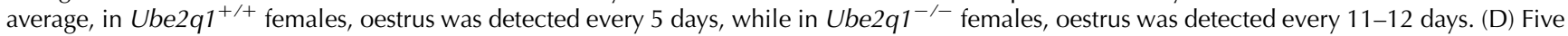
Ube $2 q 1^{-/-}$and five Ube $2 q 1^{+/+}$females were mated with vasectomized males and vaginal plugs (VP) were controlled daily for a period of 60 days. Regular mating, indicated by the presence of VP (filled, X-marked boxes), was observed in wild-type females. The mutant females demonstrated irregular mating behaviour and no average mating frequency could be estimated. ${ }^{* *}$ Significance level with $P<0.001$.

homozygous mutant male was mated with wild-type female, the litter size was slightly but significantly lower than that in the wild-type breeding pairs $(P=0.03)$ but was not significantly different from heterozygous or heterozygous and wild-type breeding $(P>0.05$, Fig. 3A, Supplementary Table 1, see section on supplementary data given at the end of this article). The weight of pups born by all kinds of breeding pairs was recorded at the morning, when the litter was noticed in the cage. The weight of newborns was not significantly different between homozygous mutant, heterozygous and wildtype crosses $(1.6 \pm 0.09,1.8 \pm 0.25$ and $1.8 \pm 0.31 \mathrm{~g}$ respectively, $P=0.23$ ). However, most of the pups of homozygous mutant females died within the first $48 \mathrm{~h}$ after parturition; thus, the number of animals surviving the first 30 days was reduced (Fig. 3B). Dead pups were dehydrated and no milk was observed in their stomach. This observation indicated that homozygous mutant females were not able to properly feed their pups. Histological analysis of the mammary gland did not reveal any abnormalities in homozygous mutant females (data not shown). It should be noticed that the weight of pups from homozygous mutant breeding, which survived 30 days after birth, was not significantly different from the weight of pups born to wild-type animals at the same age (data not shown). It is well known that hormones are controlling many aspects of mother-offspring relations and lactation; therefore, we analysed the serum prolactin (PRL) level. Blood of eight Ube2 $q 1^{-/-}$and five Ube $2 q 1^{+/+}$females was collected 1 day after parturition (lactation day 1). The PRL concentration was significantly lower in homozygous mutant females when compared with that in wild-type animals $(2.2 \pm 0.4$ vs $11.6 \pm 6.9 \mathrm{ng} / \mathrm{ml}$ respectively, $P<0.001)$. This finding suggested that the hormonal homeostasis might be impaired in homozygous mutant females; therefore, the oestrus cycle was analysed. Ten Ube $2 q^{-/-}$and three Ube $2 q 1^{+/+}$females were subjected for vaginal smear examination. The smear was taken daily at $1400 \mathrm{~h}$ for a period of 20 days. 
As demonstrated in Fig. 3C, oestrus was detected every 5 days in wild-type females. In contrast, mutant females demonstrated prolonged dioestrus phase and oestrus was detected approximately every 11-12 days. To check whether the prolonged oestrus cycle affects the sexual behaviour, five Ube2 $q 1^{-/-}$females were mated with vasectomized males and vaginal plug (VP) was controlled daily for a period of 60 days. In a control group, wild-type females $(n=5)$ mated with vasectomized males regularly, on an average every 11-12 days. In contrast, homozygous mutant females revealed irregular mating (Fig. 3D). The mating frequency of mutant females was highly differentiated between females, and even the same female demonstrated irregular mating frequency during the time of observation. No average value could be estimated from the mating frequency for homozygous mutant females. These results indicate the disturbance of the oestrus

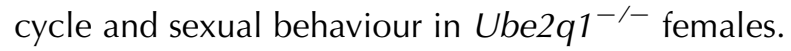

\section{Ovulation is not affected in Ube2q $1^{-/-}$females}

The impaired oestrus cycle in Ube $2 q 1^{-/-}$females might explain why they needed longer time to become pregnant and why many copulations did not result in pregnancy. However, this phenotype could not be a reason for the reduced litter size of homozygous mutant females. To elucidate the underlying cause of the reduced litter size, Ube $2 q 1^{-1-}$, Ube $2 q 1^{+/-}$and Ube $2 q 1^{+/+}$females were mated with vasectomized males and the number of ovulated oocytes was determined at the day of VP. No significant difference was noticed in the number of ovulated oocytes of Ube $2 q 1^{-/-}$when compared with Ube $2 q 1^{+/-}$or Ube $2 q 1^{+/+}$females (Table 1). Next, we analysed the response for the hormonal treatment in mutant females. No significant difference in the number of oocytes isolated from superovulated homozygous mutant and control females was observed (Table 1). These results demonstrate that ovulation is not affected in Ube2q1-deficient females.

Table 1 Number of ovulated oocytes of Ube2q1 knockout mice.

\begin{tabular}{lccccc}
\hline & \multicolumn{2}{c}{$\begin{array}{c}\text { No. of oocytes after } \\
\text { mating with } \\
\text { vasectomized }\end{array}$} & & \multicolumn{2}{c}{$\begin{array}{c}\text { No. of oocytes after } \\
\text { superovulation }\end{array}$} \\
\cline { 2 - 3 } \cline { 5 - 6 } Female genotype & Mean \pm s.D. & $n$ & & Mean \pm s.D. & $n$ \\
\hline Ube $2 q 1^{+/+}$ & $9.0 \pm 0.8$ & 4 & & $38.7 \pm 5.8$ & 3 \\
Ube $2 q 1^{+/-}$ & $7.7 \pm 1.3$ & 4 & & NA & \\
Ube $2 q 1^{-/-}$ & $8.0 \pm 1.1$ & 6 & & $42 \pm 1.4$ & 3 \\
\hline
\end{tabular}

Oocytes were isolated from VP-positive females after mating with vasectomized males. No significant differences were observed between wild-type, heterozygous and homozygous females $(P>0.05)$. Similarly, no significant difference in oocytes number after superovulation was observed between wild-type and homozygous mutant females $(P>0.05)$. Data are given as a mean number of oocytes per female \pm s.D. NA, not analysed; $n$, number of analysed animals.

\section{Impaired implantation of Ube2q1-deficient embryos}

We analysed the progress of embryonic development in the uteri of mutant females. Homozygous knockout females were mated with wild-type and homozygous knockout males. As a control, wild-type males and females were mated. After VP examination, females were killed at the gestation day 5.5, 7.5, 10.5 and 17.5, and the number of embryos was recorded. As demonstrated in Fig. 4A, a significant reduction in the number of implanted embryos was observed at E5.5, E7.5 and E10.5 in the uteri of homozygous mutant females mated with homozygous mutant males. No indications of embryonic lethality were observed after morphological and histological examination of the uteri of homozygous mutant female at the gestation day 5.5 (Fig. 4B and C, Supplementary Figure 1, see section on supplementary data given at the end of this article). Moreover, histological examination of implanted homozygous mutant embryos at E7.5 revealed that the development was comparable to the wild-type embryos (Fig. 4D). Therefore, we concluded that reduced number of implanted homozygous mutant embryos is a result of impaired pre-implantation development and/or implantation failure. In contrast, in the breeding of Ube $2 q 1^{-1-}$ female with Ube2 $q 1^{+/+}$male, the number of developing heterozygous embryos at the E10.5 was not significantly different from the control wild-type breeding (Fig. 4A). However, at E17.5, markedly increased number of degenerating heterozygous embryos in uteri of homozygous mutant females was found and the number of living embryos was significantly reduced. We reasoned that embryonic lethality is the underlying cause for the reduced number of newborns in pairs of

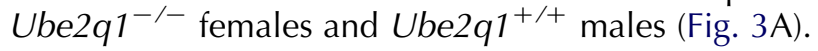

To analyse pre-implantation development of homozygous mutant embryos, the Ube $2 q 1^{-/-}$females

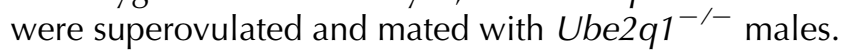
Control pairs consisted of superovulated wild-type females mated with wild-type males. Embryos at twocell stage were flushed out from oviducts of plugged females at E1.5 and cultured till E3.5. Embryos were examined and scored each day. Three Ube $2 q 1^{-1-}$ and four Ube2q $1^{+/+}$females possessed fertilized oocytes and were considered for the analysis. The results are given in Table 2 as the average number of embryos per female. As demonstrated, until the blastocyst stage, no significant difference could be observed in the development of Ube $2 q 1^{-/-}$and Ube $2 q 1^{+/+}$embryos.

As Ube $2 q 1^{-1-}$ pre-implantation embryonic development was normal and the number of implanted embryos at the early post-implantation stage (E5.5) was already reduced, we concluded that the underlying cause of reduced litter size was the implantation failure of Ube $2 q^{1-1-}$ embryos. To further validate this hypothesis, we analysed the ratio of genotypes of newborns obtained from heterozygous animals. From such a breeding pairs, 


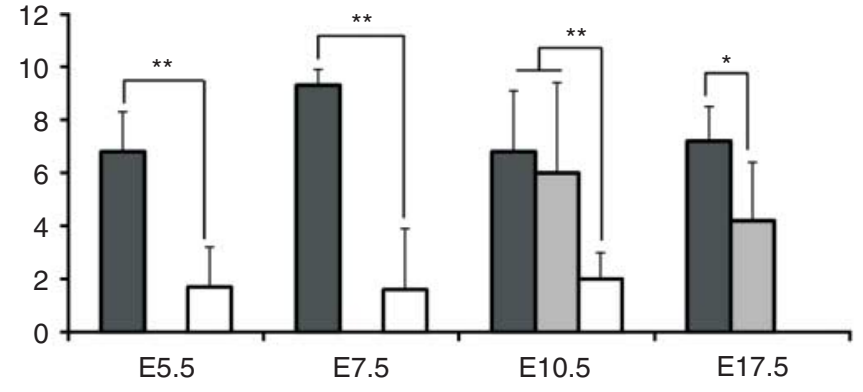

Breeding (male $\times$ female): $\square+/+X+/+\square-/-X+/+\square-/-X-/-$

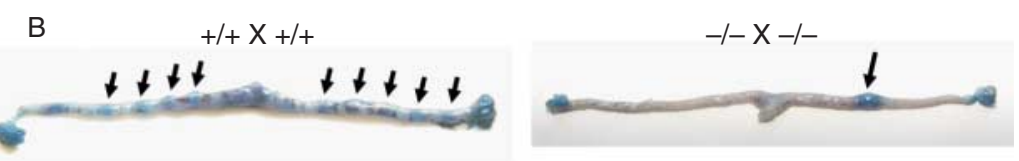

C
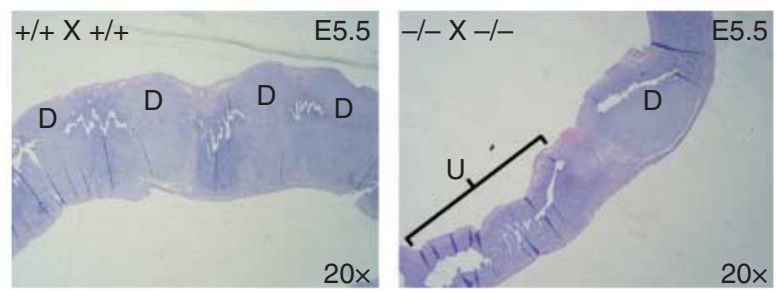

D
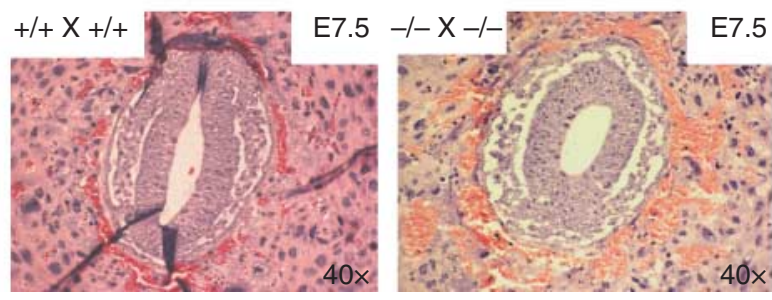

Figure 4 Analysis of embryo development in the uterus of Ube2 $\mathrm{q1}^{-1-}$ females. (A) The number of post-implantation embryos per female was recorded. Compared with wild-type breeding, significant reduction of implanted embryos was observed in homozygous mutant pairs at E5.5, E7.5 and E17.5. In the pairs of homozygous mutant female and wild-type male, the number of embryos at E10.5 was not different from wild-type breeding but was significantly reduced at E17.5. (B) Implantation sites in uteri of female at E5.5 are indicated by arrows. A significant reduction in the number of implanted embryos was observed in homozygous mutant breeding pairs when compared with wild-type breeding, but no indication of degenerating embryos was noticed in the uterus. (C) Histological analysis of the uteri at E5.5 of pregnant homozygous mutant females mated with homozygous mutant males also revealed no marks of embryonic lethality, but reduced number of implanted embryos was noted. As a control, uteri of wild-type females mated with wild-type males were analysed. (D) Normal development of implanted embryos was observed at E7.5 in both homozygous mutant and wild-type females. *Significance level with $P<0.05,{ }^{* *}$ significance level with $P<0.001, U$, uterine epithelium; $\mathrm{D}$, decidua. The magnification is given in lower right, the stage of embryonic development in upper right and the type of breeding in upper left corner. wild-type, heterozygous and homozygous mutant pups are expected in the 1:2:1 proportion. Among 109 animals that were born, only 15 , instead of expected 27 , were homozygous. The $\chi^{2}$ analysis revealed that observed deviation from the expected number of homozygous mutant pups was significant $(P=0.02)$.

\section{Mouse Ube2q1 is necessary for embryo implantation and maintenance of pregnancy}

To verify our hypothesis, that the Ube2q1 might play a role in embryonic implantation and pregnancy maintaining, we analysed the expression pattern of the Ube2q1 gene during mouse embryonic development. First, we analysed the expression in the uterus of pregnant female at E10.5. The RNA was subjected to cDNA synthesis followed by PCR with AltPCRFP and AltPCRRP primers. The expression of mouse Ube $2 q 1$ was clearly detectable in uterus at the gestation day 10.5 but not in the uterus of non-pregnant female (Fig. 5A). Next, RNA isolated from embryos at different developmental stages was analysed by RT-PCR with AltRTPCRFP and AltRTPCRRP primers or northern blot using cDNA fragment containing exons 4-9 of Ube2q1 as a probe. The expected 467 bp product representing the Ube2q1 cDNA was observed in unfertilized oocyte, four-cell stage, blastocyst and E8.5 embryo (Fig. 5B). As a positive control for RT-PCR, testis cDNA was amplified, while in negative control testicular RNA was processed in the absence of reverse transcriptase. The cDNA quality was checked using Hprt-specific primers (Fig. 5A and B). In northern blot analysis, both 4 and $2.4 \mathrm{~kb}$ Ube $2 q 1$ transcripts were detected in RNA isolated from ES cells and from all analysed stages of embryonic development. RNA quality was tested by rehybridization of the membrane with EEF2 probe (Fig. 5C). The expression of Ube2q1 was detected in the placenta of E9.5 and E10.5 with RT-PCR using AltRTPCRFP and AltRTPCRRP 
Table 2 The analysis of pre-implantation embryonic development in Ube2q1 knockout line.

\begin{tabular}{|c|c|c|c|c|c|c|}
\hline \multirow[b]{2}{*}{$\begin{array}{l}\text { Time of pre-implantation } \\
\text { embryonic development (days) }\end{array}$} & \multicolumn{6}{|c|}{ Number of embryos (mean \pm s.D.) } \\
\hline & Breeding & $\begin{array}{l}\text { Not developing } \\
\text { eggs }\end{array}$ & Two-cell & 4/8-cell & Morula & Blastocyst \\
\hline \multirow[t]{3}{*}{ E1.5 } & $+/+x+/+$ & $28.4 \pm 14.2$ & $9.4 \pm 6.4$ & - & - & - \\
\hline & $-1-x-1-$ & $50.0 \pm 12.7$ & $5.5 \pm 4.9$ & - & - & - \\
\hline & $P$ & 0.096 & 0.461 & - & - & - \\
\hline \multirow{3}{*}{ E2.5 } & $+/+x+/+$ & $11.1 \pm 9.6$ & $4.4 \pm 4.8$ & $7.0 \pm 5.8$ & - & - \\
\hline & $-1-x-1-$ & $21.0 \pm 19.8$ & $1.5 \pm 2.1$ & $5.0 \pm 1.0$ & - & - \\
\hline & $P$ & 0.326 & 0.453 & 0.658 & - & - \\
\hline \multirow[t]{3}{*}{ E3.5 } & $+/+x+/+$ & $10.7 \pm 11.7$ & $4.1 \pm 5.1$ & $2.0 \pm 2.6$ & $4.7 \pm 5.6$ & $2.7 \pm 3.3$ \\
\hline & $-1-x-1-$ & $14.5 \pm 14.8$ & $5.5 \pm 4.9$ & $2.0 \pm 2.8$ & $3.0 \pm 1.4$ & $2.5 \pm 0.7$ \\
\hline & $P$ & $0.71 \overline{1}^{-}$ & $0.7 \overline{47}$ & 1.000 & $0.6 \overline{93}$ & 0.934 \\
\hline
\end{tabular}

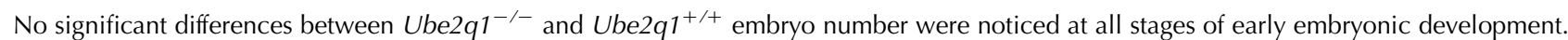
Data are given as mean number of embryos per female \pm s.D.

primers. The cDNA quality was verified by RT-PCR with Hprt-specific primers (Fig. 5D). The expression analyses clearly indicated that mouse Ube2q1 is expressed in pre- and post-implantation embryos and might have a role in placenta formation.

\section{Discussion}

The expression of $U b c 25$ gene, the Caenorhabditis elegans homologue of mouse Ube2q1, was detected not only in early embryos but also in neurons and muscles of later embryos and adult animals (Schulze et al. 2003). RNAi-mediated down-regulation of the Ubc25 gene caused late-onset paralysis of muscular functions such as locomotion, egg laying and defecation in C. elegans. Mouse and C. elegans genes share $42 \%$ similarity (Schulze et al. 2003). Here, we generated and analysed an Ube2q1 knockout mouse model and demonstrated that this widely expressed gene is involved in different aspects of female fertility. Ube $2 q 1^{-1-}$ females showed irregularity of the oestrus cycle, abnormal mating behaviour, decreased litter size and delayed occurrence of the first pregnancy. The absence of UBE2Q1 protein in the uterus of pregnant female impaired the development of heterozygous embryos. Moreover, we demonstrated that the majority of UBE2Q1-deficient embryos failed to implant in the uterus of homozygous mutant female.

By searching the NCBI database (http://www.ncbi. nlm.nih.gov) with the sequence of mouse UBE2Q1, we identified similar proteins in a wide variety of different species. The protein is highly conserved within mammals, showing $61-99 \%$ similarity of mouse amino acid composition to dog, grey short-tailed opossum, panda, rabbit, marmoset, macaque, human and rat proteins. High similarity of mouse UBE2Q1 was also found with proteins derived from birds (chicken and zebra finch), fish (zebrafish), nematodes (five species), Enteropneusta (Acorn worm), insects (20 species from five orders), Arachnida (deer tick), urchin (sea urchin) and Anemone (starlet sea anemone) (Supplementary Table 2, see section on supplementary data given at the end of this

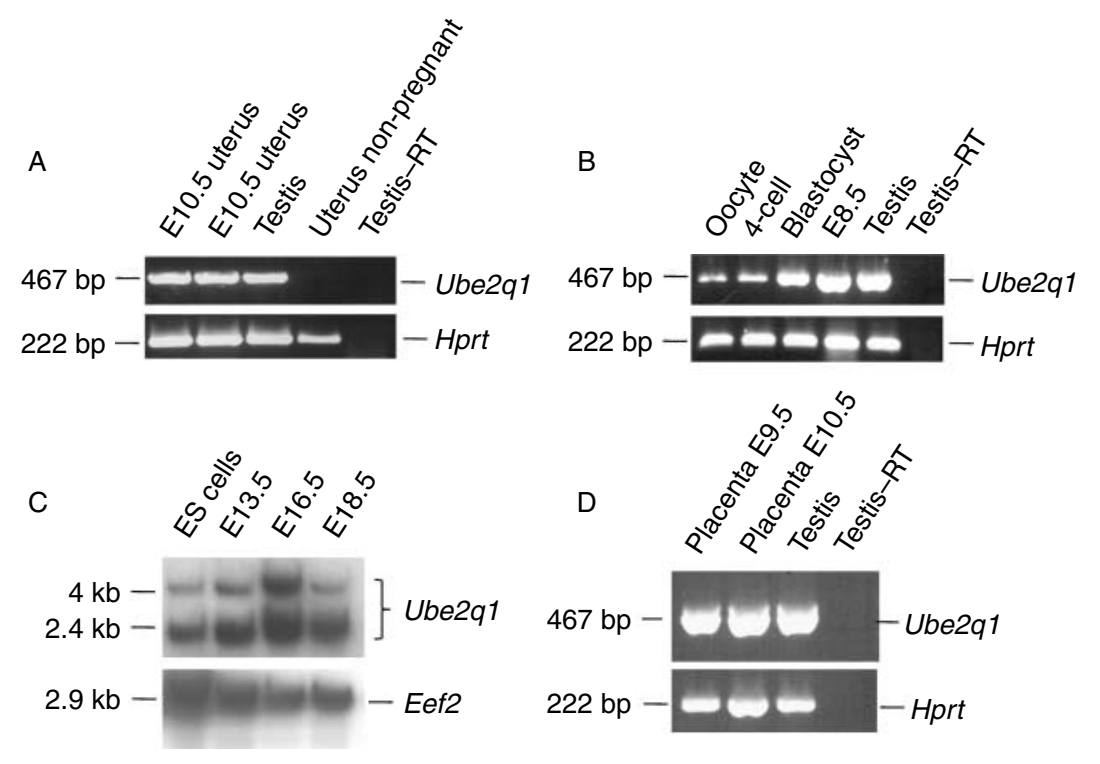

Figure 5 The expression of mouse Ube2q1 during embryonic development. RT-PCR and northern blot techniques were applied to analyse the Ube2q1 expression in the uterus of pregnant female and in developing embryos. (A) A 467 bp PCR product of Ube2q1 cDNA was detected in the uterus of E10.5 pregnant wild-type female but not in the uterus of non-pregnant female. (B) The Ube2q1 cDNA was detected in unfertilized oocytes and in all stages of embryonic development analysed by RT-PCR (B) and northern blot (C, upper panel) techniques. In the northern blot experiment, the RNA quality was proven by membrane rehybridization with human EEF2 probe (C, lower panel). (D) Mouse Ube2q1 is also expressed in the placenta at E9.5 and E10.5. In all RT-PCR, the CDNA quality was verified with Hprtspecific primers (A, B, D, lower panels). Testis RNA was used as a positive control (Testis), while testicular RNA processed in the absence of reverse transcriptase served as a negative control (testis - RT). 
article). Human cDNA probe detected Ube2q1 transcript in different species, confirming evolutionary conservatism of this gene. This finding is in agreement with the previous work (Schulze et al. 2003) and it is well known that evolutionary conserved genes play an important role in different cellular processes.

Human UBE2Q1 gene was found to be expressed in all tissues analysed. This is in agreement with previously published data demonstrating UBE2Q1 transcripts in variety of human tissues by analysis of large cDNA libraries (Strausberg et al. 2002, Gerhard et al. 2004, Ota et al. 2004). In the UniGene database (http://www.ncbi. nlm.nih.gov/UniGene), human UBE2Q1 EST clones were isolated from 37 different tissues and organs. The expression of mouse Ube2q1 gene was previously reported by Wassler et al. (2008), where the authors showed Ube2q1 transcription in thymus, lung, kidney, testis, ovary and E12.5 embryo but could not detect the Ube2q1 mRNA in liver, brain, heart and spleen. This might be a result of the low sensitivity of the northern blot technique used in this work. In the UniGene database, EST clones corresponding to the mouse Ube2q1 were identified in 32 different tissues including liver, brain, heart and spleen. Moreover, except for the uterus of non-pregnant female, we detected the expression of Ube2q1 in all tissues analysed by RT-PCR, which is more sensitive than northern blot. Therefore, we concluded that both human and mouse UBE2Q1/Ube $2 q 1$ genes are widely expressed.

The targeted disruption of mouse Ube2q1 was found to affect different aspects of female reproduction. Reduced PRL level in mutant females at the beginning of lactation indicated the altered hormonal regulation. Female mice with the knockout of PRL receptor (Prlr) also demonstrated multiple reproductive defects (Ormandy et al. 1997), namely cycle irregularities, fertilization problems and complete failure of embryonic implantation. The newborn lethality and lactation problems were noticed in heterozygous Prlr knockout females (Ormandy et al. 1997). The lower serum PRL concentration 1 day after parturition and the similarities in the phenotype of Ube2q1 and PrIr knockout mice indicated that at least partially similar pathway might be affected in both mutants. Ubiquitination involvement in hormone regulation is well documented in steroid hormone homeostasis. Estrogens and progesterone act through receptor proteins known as the nuclear hormone receptors (NHRs; Lydon et al. 1995, Korach et al. 1996). These receptors might recruit co-activators that facilitate the assembly of the transcription complex to the target genes (Tsai \& O'Malley 1994, Beato et al. 1995, Mangelsdorf et al. 1995, Kinyamu \& Archer 2004). Co-activators are diverse proteins mediating the transcriptional process through a wide array of enzymatic activities such as acetylation, methylation, ubiquitination, phosphorylation and chromatin remodelling (Ogryzko et al. 1996, Spencer et al. 1997, McKenna et al. 1999, Chen 2000, Lonard \& O'Malley 2007). The Ub protein ligase E3A (UBE3A) was reported to act as steroid hormone co-activator (Nawaz et al. 1999). Furthermore, the overexpression or knockout of Ube3a altered the level of oestrogen (ER- $\alpha$ ) and progesterone (PR-B) receptors (Ramamoorthy et al. 2010). The authors demonstrated that PR-B level is regulated by the UBE3A via the Ub-proteasome pathway. The irregular oestrus cycle and abnormal mating behaviour of the Ube $2 q^{-1-}$ females might indicate aberrant steroid hormone signalling.

It was demonstrated that in mouse embryonic stem cells, the expression of B4galt 1 inversely correlated with the expression of Ube2q1 (Wassler et al. 2008). Our findings about the expression of Ube $2 q 1$ in early embryos are in agreement with that finding. It was suggested by the authors that Ube2q1 might be involved in ubiquitination and degradation of B4GALT1 through the 26S proteasome pathway or that the UBE2Q1B4GALT1 binding can influence the internalization of the B4GALT1 (Wassler et al. 2008). The B4GALT1 is involved in cell adhesion (for review see Shur (1991)) and was detected in pre-implantation embryos (Bayna et al. 1988), ectoplacental cone cells (Hathaway et al. 1989) and uterine epithelial cells (Dutt et al. 1987); therefore, proper turnover of this protein might be critical for embryo implantation. Our results strongly suggest that Ube2q1, an E2 conjugating enzyme, is important for embryo implantation as most of the Ube $2 q^{-1-}$ blastocysts failed to implant in the uterus. But this gene might also be important for further embryonic development because we showed that the expression of mouse Ube2q1 is induced in the uterus of pregnant mouse. This result is supported by the existence of two Ube2q1 EST clones, Al157754.1 and Al197002.1, that were generated using RNA isolated from pregnant mouse uterus. The Ub homologue (Ub cross-reactive protein) ISG15 was also induced by pregnancy in the uterus in cow (Austin et al. 1996, Hansen et al. 1997, Johnson et al. 1998, Perry et al. 1999, Thatcher et al. 2001), mouse (Austin et al. 2003) and primates (Bebington et al. 1999a, 1999b). It seems that protein turnover is important for the endometrium response and maintaining pregnancy. In the uterus of Ube $2 q^{-1-}$ females, normal implantation of heterozygous embryos occurred but they degenerated after E10.5, indicating that Ube2q1 uterine expression is necessary for the maintenance of pregnancy.

In humans, $30-50 \%$ of conceptions end in spontaneous abortions before the end of the first trimester (Gupta et al. 2007), and in general, the spontaneous abortion rate of clinical pregnancies is about $15-20 \%$ (Dickey et al. 1996). The most common reasons for spontaneous abortions are chromosomal abnormalities, but about $50 \%$ of cases remain idiopathic (Cramer \& Wise 2000, Gupta et al. 2007). The majority of pregnancy losses occur before or during implantation 
(Gupta et al. 2007, Makrigiannakis et al. 2008); therefore, the progress towards improving the success rate of early pregnancies is a very important aim of reproductive medicine. In the review by Makrigiannakis et al. (2008), the authors suggested that generation of knockout animals in which early embryonic lethality is observed would enable the analyses of genes controlling implantation and would be helpful to decode fertility defects. According to our results, the UBE2Q1 may be one of the candidate genes for mutation screening in women with recurrent spontaneous abortions and/or implantation failure.

The importance of better understanding of the ubiquitination pathway is emphasized by the large number of human diseases related to aberrant protein degradation. The searching of Online Mendelian Inheritance of Man (OMIM, http://www.ncbi.nlm.nih.gov/ omim/) database with the term ' $\mathrm{Ub}^{\prime}$ ' resulted in 757 hits. The expression of $U B E 2 Q 1$ in many tissues suggests that this gene plays a role not only in female fertility. However, the phenotype in different organs of mutant mouse might be not so prominent and thus difficult to detect. This hypothesis is supported by the observation that human UBE2Q1 gene, which is down-regulated by miR-338, can degrade key enzymes essential for neurite growth and thus negatively control this process (Barik 2008). UBE2Q1 was also found, among many other genes related to ubiquitination pathway, to be altered in human airway epithelia cells in cystic fibrosis patients (reviewed in Hampton \& Stanton (2010)). Recently, the frame shift mutation in UBE2Q1 gene was identified in gastric carcinoma (Yoo et al. 2011). Moreover, the interaction of UBE2Q1 with STIP1 homology and $\mathrm{U}$-box containing protein $1, \mathrm{E} 3 \mathrm{Ub}$ protein ligase (STUB1), which is involved in caytaxin ubiquitination, was demonstrated by pull down and yeast two-hybrid techniques (Grelle et al. 2006). Mutations in ATCAY gene, encoding caytaxin, cause Cayman disease (Bomar et al. 2003). Taken together, our mouse model can be utilized to better understand the function of ubiquitination process in proteome regulation in different organs.

\section{Materials and Methods}

\section{Expression analysis}

Total RNA was extracted from several different mouse tissues; mouse embryos at E13.5, E16.5, E18.5 and from testis or brain of rhesus (Macaca mulatta), bovine (Bos sp.), pig (Sus sp.), rat (Rattus norvegicus), goat (Capra aegagrus hircus), rabbit (Oryctolagus cuniculus) and pigeon (Columba livia) using the RNA now kit (Biomol, Hamburg, Germany). In addition, RNA was isolated from the uterus of pregnant female mice at gestation day 10.5, dissected without any fragments of developing embryos. The RNA from oocytes, two-cell and four-cell stage embryos and placentas from embryos at E9.5 and E10.5 was isolated using the peqGOLD TriFast reagent (Peqlab, Erlangen, Germany) according to the manufacturer's recommendations.
For northern blot analyses, $20 \mu \mathrm{g}$ total RNA was separated in $1.5 \% \mathrm{MOPS} /$ formaldehyde agarose gel and transferred onto nitrocellulose membrane (Hybond $\mathrm{N}$, Amersham). For the UBE2Q1 expression analysis in human tissues, multiple tissues northern blots (2 $\mu \mathrm{g}$ polyA RNA for each tissue) (BD Biosciences Clontech, Heidelberg, Germany) were used. Membrane with human RNA was hybridized with radioactive-labelled $1 \mathrm{~kb}$ Pvull restriction fragment of human UBE2Q1 cDNA, containing exons 5-13, and mouse RNA was hybridized with Ube2q1 cDNA fragment (exons 4-9) amplified with AltRTPCRFP (AGAGCAGTGCACGCAGGAAG) and AltRTPCRRP (TGACGAACGGTGGGTCAAAG) primers. The filters were subsequently rehybridized with ${ }^{32} \mathrm{P}$-labelled ACTB cDNA (GenelD:60) clone (IMAGp998L23787) or $1.6 \mathrm{~kb}$ BamHI/Bglll fragment of EEF2 cDNA (GenelD 1938) probes.

For RT-PCR, DNasel-treated total RNA was primed with oligo$\mathrm{dT}$ primer and reverse transcribed at $42{ }^{\circ} \mathrm{C}$ for $1 \mathrm{~h}$ using the Superscript reverse transcriptase system (Invitrogen). cDNA $(1 \mu \mathrm{l})$ was used in a PCR with AltRTPCRFP and AltRTPCRRP primers, generating a $467 \mathrm{bp}$ product. Simultaneously, the reaction without reverse transcriptase was performed to rule out template contamination in reaction components or DNA contamination in RNA samples (negative control). To verify cDNA quality, mHPRTFor-Q (AGCCCCAAAATGGTTAAGGTTGC3) and mHPRT-Rev-Q (TTGCAGATTCAACTTGCGCTCAT) primers amplifying a 222 bp fragment of mouse Hprt gene (GenelD: 15452) were used.

\section{Generation of Ube2q1-deficient mouse}

The recombinant phage clone, containing mouse Ube $2 q 1$ gene, was identified by hybridization of the mouse genomic library (kindly provided by Prof. Braun, Bad Nauheim, Germany) with $1 \mathrm{~kb}$ Pvull fragment of UBE2Q1 cDNA. This library contains Sall/BamHI genomic fragments from 129/Sv] mouse cloned in EMBL3 Phage vector. From this recombinant phage clone, a $5 \mathrm{~kb}$ Xhol fragment located upstream exon 5 as well as a $4 \mathrm{~kb}$ Xbal fragment located downstream exon 11 of Ube $2 q 1$ were isolated and used as a $5^{\prime}$ and $3^{\prime}$ homologous parts of the knockout vector respectively. Both fragments were subcloned into the pPNT Vector and verified by sequencing. The obtained targeting vector was linearized using Notl and electroporated into R1 ES cells (Wurst \& Joyner 1993). Membranes with EcoRI digested DNA, isolated from ES cell colonies resistant to $\mathrm{G} 418(400 \mathrm{mg} / \mathrm{ml})$ and ganciclovir $(2 \mu \mathrm{M})$ were hybridized with $2.4 \mathrm{~kb}$ EcoRl/Xhol fragment containing part of Ube2q1 exon 1 and the upstream sequence. This external probe recognized an $8 \mathrm{~kb}$ fragment of Ube $2 q 1$ wildtype allele and a $13 \mathrm{~kb}$ fragment of homologous recombinant allele. ES cells carrying the disrupted Ube2q1 allele were used for generation of chimaeras. Male chimaeras were mated with 129Sv females and mice from F1 generation were genotyped by Southern blot (as described for ES cells) and PCR with primers gM7F (TGATAAGTGAAGATAACGATAGAAG), gM8R (TGGCTTGGCGGCTTGCTGAG) and Pgk3 (GGATGTGGAATGTGTGCGAGG). Using these primers, a $498 \mathrm{bp}$ fragment of the wild-type allele and a $308 \mathrm{bp}$ mutant allele were amplified. Heterozygous animals were crossed to obtain homozygous mutants. 


\section{Oocytes and embryos analyses}

For the analysis of ovulated oocytes, females were mated with vasectomized males and examined daily for the presence of VP. The day of VP was designed as E0.5, and at this day, oocytes were isolated and counted separate for each female. To ascertain the oocyte number after superovulation, females were injected with $7.5 \mathrm{IU}$ pregnant mare serum gonadotrophin (PMS; Intergonan; Intervet, Toenisvorst, Germany) followed $48 \mathrm{~h}$ later with $7.5 \mathrm{IU}$ human chorionic gonadotrophin (hCG) (Predalon; Organon, Oberschleissheim, Germany). Thirteen hours after hCG administration, oocytes were isolated and counted. For the analysis of pre-implantation embryonic development, females were superovulated (as described earlier) and mated with males. Embryos at E1.5 were flushed out from oviducts of plugged females and cultivated in M16 medium (Sigma) till E3.5. Embryos were evaluated daily and classified as not developing eggs (degenerating embryos and not fertilized oocytes), two-cell, 4/8-cell, morula and blastocyst stage embryos. For the analysis of post-implantation embryonic development, females were mated with males, VP was inspected daily and positive females were killed at the gestation days 5.5, 7.5 and 10.5. Then, uteri were dissected and embryos were counted from at least five females of each genotype and embryonic developmental stage. Implantation sites at E5.5 were visualized by i.v. injection of $1 \%$ Evans blue in PBS (Sigma) $5 \mathrm{~min}$ before cervical dislocation (Ye et al. 2005). Females without any embryos were considered as nonpregnant and were not included in the statistics.

\section{Oestrus cycle analysis}

The oestrus cycle was determined by observation of vaginal smears (Archunan \& Dominic 1991). The smears were prepared with PBS and examined directly under light microscopy by trained observer. Four stages were determined: proestrus, oestrus, metoestrus and dioestrus. Females were first trained for 2 weeks to accustom to daily vaginal smear examination, and then oestrus cycle was examined for 20 days. Females that were never in oestrus phase during the time of observation were excluded from the analysis.

\section{PRL RIA}

Blood was collected in heparinized tubes, centrifuged $(3000 \mathrm{~g}$, $20 \mathrm{~min}$ ) and the serum was stored at $-20^{\circ} \mathrm{C}$ until further analysis. PRL was measured by RIA using mouse-specific reagents provided by National Institute of Diabetes and Digestive and Kidney Diseases (NIDDK) National Hormone and Pituitary Program (NHPP; Dr A F Parlow, NHPP, Torrance, CA, USA). Assays were performed using $50 \mu \mathrm{l}$ serum in duplicate. Results are expressed in terms of mouse PRL RP 3 (RP3). Intra- and interassay coefficients of variation were 7.2 and $12.8 \%$ respectively. The results are given as mean \pm s.D.

\section{Histological analysis of post-implantation embryos}

Uteri were dissected from pregnant females at E5.5 and E7.5. Probes were fixed in Bouin's solution, embedded in paraffin and processed routinely for histological examination (haematoxylin and eosin (HE) staining).

\section{Statistical analysis}

Data distribution was tested using the Shapiro-Wilk $W$ test with extension described by Royston (1982). All data were not significantly different from normal distribution. For the evaluation of two groups, the $t$-test was used; when three or more groups were compared, the ANOVA analysis was applied. To test whether genotypes of newborns obtained from heterozygous breeding pairs deviated from the expected Mendelian ratio $1: 2: 1$, the $\chi^{2}$ test was used. The $P$ value below 0.05 was considered as significant. All statistical analyses were performed using the Statistica 9 software package (StatSoft, Inc., Tulsa, OK, USA).

\section{Supplementary data}

This is linked to the online version of the paper at http://dx.doi. org/10.1530/REP-12-0054.

\section{Declaration of interest}

The authors declare no conflict of interest that could be perceived as prejudicing the impartiality of the research reported.

\section{Funding}

This research was supported by a grant (SFB272) from the DFG (German Research Foundation) to Wolfgang Engel.

\section{Acknowledgements}

The authors thank A Golas for critical reading of the manuscript.

\section{References}

Archunan G \& Dominic CJ 1991 Male-induced termination of pseudopregnancy in laboratory mice: investigations on the pseudopregnancy induced by group-housing and that induced by sterile mating. Advances in the Biosciences 10 1-12.

Austin KJ, Ward SK, Teixeira MG, Dean VC, Moore DW \& Hansen TR 1996 Ubiquitin cross-reactive protein is released by the bovine uterus in response to interferon during early pregnancy. Biology of Reproduction 54 600-606. (doi:10.1095/biolreprod54.3.600)

Austin KJ, Bany BM, Belden EL, Rempel LA, Cross JC \& Hansen TR 2003 Interferon-stimulated gene-15 (Isg15) expression is up-regulated in the mouse uterus in response to the implanting conceptus. Endocrinology 144 3107-3113. (doi:10.1210/en.2002-0031)

Barik S 2008 An intronic microRNA silences genes that are functionally antagonistic to its host gene. Nucleic Acids Research 36 5232-5241. (doi:10.1093/nar/gkn513)

Bayna EM, Shaper JH \& Shur BD 1988 Temporally specific involvement of cell surface $\beta-1,4$ galactosyltransferase during mouse embryo morula compaction. Cell 53 145-157. (doi:10.1016/0092-8674(88)90496-5)

Beato M, Herrlich P \& Schütz G 1995 Steroid hormone receptors: many actors in search of a plot. Cell 83 851-857. (doi:10.1016/00928674(95)90201-5) 
Bebington C, Bell SC, Doherty FJ, Fazleabas AT \& Fleming SD 1999a Localization of ubiquitin and ubiquitin cross-reactive protein in human and baboon endometrium and decidua during the menstrual cycle and early pregnancy. Biology of Reproduction 60 920-928. (doi:10.1095/ biolreprod60.4.920)

Bebington C, Doherty FJ \& Fleming SD 1999 b Ubiquitin cross-reactive protein gene expression is increased in decidualized endometrial stromal cells at the initiation of pregnancy. Molecular Human Reproduction 5 966-972. (doi:10.1093/molehr/5.10.966)

Bebington C, Doherty FJ, Ndukwe G \& Fleming SD 2000 The progesterone receptor and ubiquitin are differentially regulated within the endometrial glands of the natural and stimulated cycle. Molecular Human Reproduction 6 264-268. (doi:10.1093/molehr/6.3.264)

Bebington C, Doherty FJ \& Fleming SD 2001 The possible biological and reproductive functions of ubiquitin. Human Reproduction Update 7 102-111. (doi:10.1093/humupd/7.1.102)

Bomar JM, Benke PJ, Slattery EL, Puttagunta R, Taylor LP, Seong E, Nystuen A, Chen W, Albin RL, Patel PD et al. 2003 Mutations in a novel gene encoding a CRAL-TRIO domain cause human Cayman ataxia and ataxia/dystonia in the jittery mouse. Nature Genetics 35 264-269. (doi:10.1038/ng1255)

Burroughs AM, Jaffee M, lyer LM \& Aravind L 2008 Anatomy of the E2 ligase fold: implications for enzymology and evolution of ubiquitin/ Ub-like protein conjugation. Journal of Structural Biology 162 205-218. (doi:10.1016/j.jsb.2007.12.006)

Chen JD 2000 Steroid/nuclear receptor coactivators. Vitamins and Hormones 58 391-448. (doi:10.1016/S0083-6729(00)58032-7)

Cramer DW \& Wise LA 2000 The epidemiology of recurrent pregnancy loss. Seminars in Reproductive Medicine 18 331-339. (doi:10.1055/s-200013722)

Dickey RP, Taylor SN, Curole DN, Rye PH \& Pyrzak R 1996 Incidence of spontaneous abortion in clomiphene pregnancies. Human Reproduction 11 2623-2628. (doi:10.1093/oxfordjournals.humrep.a019182)

Dutt A, Tang JP \& Carson DD 1987 Lactosaminoglycans are involved in uterine epithelial cell adhesion in vitro. Developmental Biology 119 27-37. (doi:10.1016/0012-1606(87)90203-X)

Dye BT \& Schulman BA 2007 Structural mechanisms underlying posttranslational modification by ubiquitin-like proteins. Annual Review of Biophysics and Biomolecular Structure 36 131-150. (doi:10.1146/ annurev.biophys.36.040306.132820)

Gerhard DS, Wagner L, Feingold EA, Shenmen CM, Grouse LH, Schuler G, Klein SL, Old S, Rasooly R, Good P et al. 2004 The status, quality, and expansion of the NIH full-length cDNA project: the Mammalian Gene Collection (MGC). Genome Research 14 2121-2127. (doi:10.1101/gr. 2596504)

Grelle G, Kostka S, Otto A, Kersten B, Genser KF, Müller EC, Wälter S, Böddrich A, Stelzl U, Hänig C et al. 2006 Identification of VCP/p97, carboxyl terminus of Hsp70-interacting protein (CHIP), and amphiphysin II interaction partners using membrane-based human proteome arrays. Molecular \& Cellular Proteomics 5 234-244. (doi:10.1074/mcp. M500198-MCP200)

Gupta S, Agarwal A, Banerjee J \& Alvarez JG 2007 The role of oxidative stress in spontaneous abortion and recurrent pregnancy loss: a systematic review. Obstetrical \& Gynecological Survey 62 335-347. (doi:10.1097/ 01.ogx.0000261644.89300.df)

Hampton TH \& Stanton BA 2010 A novel approach to analyze gene expression data demonstrates that the DeltaF508 mutation in CFTR downregulates the antigen presentation pathway. American Journal of Physiology. Lung Cellular and Molecular Physiology 298 L473-L482. (doi:10.1152/ajplung.00379.2009)

Hansen TR, Austin KJ \& Johnson GA 1997 Transient ubiquitin cross-reactive protein gene expression in the bovine endometrium. Endocrinology 138 5079-5082. (doi:10.1210/en.138.11.5079)

Harbers K, Muller U, Grams A, Li E, Jaenisch R \& Franz T 1996 Provirus integration into a gene encoding a ubiquitin-conjugating enzyme results in a placental defect and embryonic lethality. PNAS 93 12412-12417. (doi:10.1073/pnas.93.22.12412)

Hathaway HJ, Romagnano LC \& Babiarz BS 1989 Analysis of cell surface galactosyltransferase activity during mouse trophectodermal differentiation. Developmental Biology 134 351-361. (doi:10.1016/00121606(89)90107-3)
Herington JL, Bi J, Martin JD \& Bany BM 2007 -Catenin (CTNNB1) in the mouse uterus during decidualization and the potential role of two pathways in regulating its degradation. Journal of Histochemistry and Cytochemistry 55 963-974. (doi:10.1369/jhc.7A7199.2007)

Hofmann RM \& Pickart CM 2001 In vitro assembly and recognition of Lys-63 polyubiquitin chains. Journal of Biological Chemistry 276 27936-27943. (doi:10.1074/jbc.M103378200)

Huber C, Dias-Santagata D, Glaser A, O'Sullivan J, Brauner R, Wu K, Xu X, Pearce K, Wang R, Uzielli ML et al. 2005 Identification of mutations in CUL7 in 3-M syndrome. Nature Genetics 37 1119-1124. (doi:10.1038/ ng1628)

Johnson GA, Austin KJ, Van Kirk EA \& Hansen TR 1998 Pregnancy and interferon-tau induce conjugation of bovine ubiquitin cross-reactive protein to cytosolic uterine proteins. Biology of Reproduction $\mathbf{5 8}$ 898-904. (doi:10.1095/biolreprod58.4.898)

Kinyamu HK \& Archer TK 2004 Modifying chromatin to permit steroid hormone receptor-dependent transcription. Biochimica et Biophysica Acta 1677 30-45. (doi:10.1016/j.bbaexp.2003.09.015)

Korach KS, Couse JF, Curtis SW, Washburn TF, Lindzey J, Kimbro KS, Eddy EM, Migliaccio S, Snedeker SM, Lubahn DB et al. 1996 Estrogen receptor gene disruption: molecular characterization and experimental and clinical phenotypes. Recent Progress in Hormone Research 51 159-186.

Lonard DM \& O'Malley BW 2007 Nuclear receptor coregulators: judges, juries, and executioners of cellular regulation. Molecular Cell 27 691-700. (doi:10.1016/j.molcel.2007.08.012)

Lydon JP, DeMayo FJ, Funk CR, Mani SK, Hughes AR, Montgomery CA Jr, Shyamala G, Conneely OM \& O'Malley BW 1995 Mice lacking progesterone receptor exhibit pleiotropic reproductive abnormalities. Genes and Development 9 2266-2278. (doi:10.1101/gad.9.18.2266)

Makrigiannakis A, Karamouti M, Drakakis P, Loutradis D \& Antsaklis A 2008 Fetomaternal immunotolerance. American Journal of Reproductive Immunology 60 482-496. (doi:10.1111/j.1600-0897.2008.00655.x)

Mangelsdorf DJ, Thummel C, Beato M, Herrlich P, Schütz G, Umesono K, Blumberg B, Kastner P, Mark M, Chambon P et al. 1995 The nuclear receptor superfamily: the second decade. Cell 83 835-839. (doi:10. 1016/0092-8674(95)90199-X)

Marenholz I, Zirra M, Fischer DF, Backendorf C, Ziegler A \& Mischke D 2001 Identification of human epidermal differentiation complex (EDC)encoded genes by subtractive hybridization of entire YACs to a gridded keratinocyte cDNA library. Genome Research 11 341-355. (doi:10. 1101/gr.114801)

McKenna NJ, Xu J, Nawaz Z, Tsai SY, Tsai MJ \& O'Malley BW 1999 Nuclear receptor coactivators: multiple enzymes, multiple complexes, multiple functions. Journal of Steroid Biochemistry and Molecular Biology 69 3-12. (doi:10.1016/S0960-0760(98)00144-7)

Melner MH, Ducharme NA, Brash AR, Winfrey VP \& Olson GE 2004 Differential expression of genes in the endometrium at implantation: upregulation of a novel member of the E2 class of ubiquitin-conjugating enzymes. Biology of Reproduction 70 406-414. (doi:10.1095/biolreprod.103.020719)

Murata S, Kawahara H, Tohma S, Yamamoto K, Kasahara M, Nabeshima Y, Tanaka K \& Chiba T 1999 Growth retardation in mice lacking the proteasome activator PA28gamma. Journal of Biological Chemistry 274 38211-38215. (doi:10.1074/jbc.274.53.38211)

Nagy A \& Rossant J 1993 Production of completely ES cell-derived fetuses. In Gene Targeting: a Practical Approach. Ed. AL Joyner. Oxford, New York, Tokyo: IRL Press.

Nawaz Z, Lonard DM, Smith CL, Lev-Lehman E, Tsai SY, Tsai MJ \& O'Malley BW 1999 The Angelman syndrome-associated protein, E6-AP, is a coactivator for the nuclear hormone receptor superfamily. Molecular and Cellular Biology 2 1182-1189.

Ogryzko VV, Schiltz RL, Russanova V, Howard BH \& Nakatani Y 1996 The transcriptional coactivators p300 and CBP are histone acetyltransferases. Cell 87 953-959. (doi:10.1016/S0092-8674(00)82001-2)

Ormandy CJ, Camus A, Barra J, Damotte D, Lucas B, Buteau H, Edery M, Brousse N, Babinet C, Binart N et al. 1997 Null mutation of the prolactin receptor gene produces multiple reproductive defects in the mouse. Genes and Development 11 167-178. (doi:10.1101/gad.11.2.167)

Ota T, Suzuki Y, Nishikawa T, Otsuki T, Sugiyama T, Irie R, Wakamatsu A, Hayashi K, Sato H, Nagai K et al. 2004 Complete sequencing and characterization of 21,243 full-length human cDNAs. Nature Genetics 36 40-45. (doi:10.1038/ng1285) 
Perry DJ, Austin KJ \& Hansen TR 1999 Cloning of interferon-stimulated gene 17: the promoter and nuclear proteins that regulate transcription. Molecular Endocrinology 13 1197-1206. (doi:10.1210/me.13.7.1197)

Pickart CM \& Eddins MJ 2004 Ubiquitin: structures, functions, mechanisms. Biochimica et Biophysica Acta 1695 55-72. (doi:10.1016/j.bbamcr. 2004.09.019)

Pru JK, Austin KJ, Haas AL \& Hansen TR 2001 Pregnancy and interferontau upregulate gene expression of members of the 1-8 family in the bovine uterus. Biology of Reproduction 65 1471-1480. (doi:10.1095/ biolreprod65.5.1471)

Ramamoorthy S, Dhananjayan SC, Demayo FJ \& Nawaz Z 2010 Isoform-specific degradation of PR-B by E6-AP is critical for normal mammary gland development. Molecular Endocrinology 24 2099-2113. (doi:10.1210/me.2010-0116)

Royston JP 1982 An extension of Shapiro and Wilk's $W$ test for normality to large samples. Applied Statistics 31 115-124. (doi:10.2307/2347973)

Schulze E, Altmann ME, Adham IM, Schulze B, Fröde S \& Engel W 2003 The maintenance of neuromuscular function requires UBC-25 in Caenorhabditis elegans. Biochemical and Biophysical Research Communications 305 691-699. (doi:10.1016/S0006-291X(03)00824-6)

Shur BD 1991 Cell surface $\beta$ 1,4 galactosyltransferase: twenty years later. Glycobiology 1 563-575. (doi:10.1093/glycob/1.6.563)

Spencer TE, Jenster G, Burcin MM, Allis CD, Zhou J, Mizzen CA McKenna NJ, Onate SA, Tsai SY, Tsai MJ et al. 1997 Steroid receptor coactivator-1 is a histone acetyltransferase. Nature 389 194-198. (doi:10.1038/38304)

Strausberg RL, Feingold EA, Grouse LH, Derge JG, Klausner RD, Collins FS, Wagner L, Shenmen CM, Schuler GD, Altschul SF et al. 2002 Generation and initial analysis of more than 15,000 full-length human and mouse cDNA sequences. PNAS 99 16899-16903. (doi:10.1073/pnas. 242603899)

Sutovsky P, Motlik J, Neuber E, Pavlok A, Schatten G, Palecek J, Hyttel P, Adebayo OT, Adwan K, Alberio R et al. 2001 Accumulation of the proteolytic marker peptide ubiquitin in the trophoblast of mammalian blastocysts. Cloning and Stem Cells 3 157-161. (doi:10.1089/ 153623001753205115)

Thatcher WW, Guzeloglu A, Mattos R, Binelli M, Hansen TR \& Pru JK 2001 Uterine-conceptus interactions and reproductive failure in cattle. Theriogenology 56 1435-1450. (doi:10.1016/S0093-691X(01)00645-8)
Tsai MJ \& O'Malley BW 1994 Molecular mechanisms of action of steroid/thyroid receptor superfamily members. Annual Review of Biochemistry 63 451-486. (doi:10.1146/annurev.bi.63.070194.002315)

Tsutsumi T, Kuwabara H, Arai T, Xiao Y \& Decaprio JA 2008 Disruption of the Fbxw8 gene results in pre- and postnatal growth retardation in mice. Molecular and Cellular Biology 28 743-751. (doi:10.1128/MCB.01665-07)

Wang HM, Zhang X, Qian D, Lin HY, Li QL, Liu DL, Liu GY, Yu XD \& Zhu C 2004 Effect of ubiquitin-proteasome pathway on mouse blastocyst implantation and expression of matrix metalloproteinases-2 and -9. Biology of Reproduction 70 481-487. (doi:10.1095/biolreprod.103.021634)

Wassler MJ, Shur BD, Zhou W \& Geng YJ 2008 Characterization of a novel ubiquitin-conjugating enzyme that regulates $\beta 1$, 4-galactosyltransferase1 in embryonic stem cells. Stem Cells 26 2006-2018. (doi:10.1634/ stemcells.2007-1080)

van Wijk SJ \& Timmers HT 2010 The family of ubiquitin-conjugating enzymes (E2s): deciding between life and death of proteins. FASEB Journal 24 981-993. (doi:10.1096/fj.09-136259)

Wurst W \& Joyner A 1993 Production of embryonic stem cell clones. In Gene Targeting: a Practical Approach, pp 33-61. Ed. A Joyner. Oxford University Press, Inc., New York: IRL Press.

Yang Q, Chen SP, Zhang XP, Wang H, Zhu C \& Lin HY 2009 Smurf2 participates in human trophoblast cell invasion by inhibiting TGF- $\beta$ type I receptor. Journal of Histochemistry and Cytochemistry 57 605-612. (doi:10.1369/jhc.2009.953166)

Ye X, Hama K, Contos JJ, Anliker B, Inoue A, Skinner MK, Suzuki H, Amano T, Kennedy G, Arai H et al. 2005 LPA3-mediated lysophosphatidic acid signalling in embryo implantation and spacing. Nature 435 104-108. (doi:10.1038/nature03505)

Yoo NJ, Park SW \& Lee SH 2011 Frameshift mutations of ubiquitinationrelated genes HERC2, HERC3, TRIP12, UBE2Q1 and UBE4B in gastric and colorectal carcinomas with microsatellite instability. Pathology 43 753-755. (doi:10.1097/PAT.0b013e32834c7e78)

Received 17 February 2012

First decision 12 March 2012

Revised manuscript received 12 September 2012

Accepted 24 October 2012 